\title{
Objective Evidence of Post-exertional "Malaise" in Myalgic Encephalomyelitis and Chronic Fatigue Syndrome
}

\section{Frank NM Twisk*}

Department of Biological Chemistry, ME-de-patiënten Foundation, Netherlands

"Corresponding author: Frank NM Twisk, Department of Biological Chemistry, ME-de-patiënten Foundation, Zonnedauw 15, 1906 HB Limmen, Netherlands, Tel: +31-72-505 4775; E-mail: frank.twisk@hetnet.nl

Rec date: Jan 14, 2015, Acc date: Apr 13, 2015, Pub date: Apr 15, 2015

Copyright: ( 2015 Twisk FNM. This is an open-access article distributed under the terms of the Creative Commons Attribution License, which permits unrestricted use, distribution, and reproduction in any medium, provided the original author and source are credited.

\begin{abstract}
Essential elements of Myalgic Encephalomyelitis (ME) are muscle (weakness) and tenderness, cognitive deficits, neurological impairments, especially of cognitive, autonomic and sensory functions, but above all, post-exertional "malaise": a prolonged increase of symptoms after a minor physical and mental exertion.

Chronic fatigue Syndrome (CFS) is defined as clinically evaluated, unexplained (persistent or relapsing) chronic fatigue, accompanied by at least four out of eight specific symptoms, e.g., sore throat, unrefreshing sleep, and headaches.

Since cognitive deficits and post-exertional "malaise" are not mandatory for the diagnosis CFS, only part of the CFS patient group meets the diagnostic criteria for ME.

So, post-exertional "malaise" is considered to be the distinctive feature of ME. However, "malaise" is an ambiguous and subjective notion. In order to assess post-exertional malaise objectively, several studies have employed widely used methods to quantify the deviant effects of exertion in ME (CFS). This review focuses on the long-lasting (negative) effects of exercise on the performance indicators of the physical exercise capacity, the cognitive deficits and the muscle power.
\end{abstract}

Keywords: Myalgic encephalomyelitis; Chronic fatigue syndrome; Exercise; Post-exertional malaise; Methods; Assessment

\section{Introduction}

ME and CFS are often qualified as enigmatic disorders [1], partly due to the fact that typical symptoms, e.g. fatigue and post-exertional "malaise", are subjective notions. A substantial part of the confusion and controversy with regard to the diagnosis, the nature and the treatment of ME and CFS originates from these subjective notions. To end this debate and to move forward it is essential to use objective methods to assess the characteristic symptoms of ME and CFS objectively, as far as possible [2]. This review aims to discuss observations with regard to the impact of exercise on the physical exercise capacity, cognitive functioning and muscle power in ME (CFS).

Post-exertional "malaise" in this article is defined as 'a pathological inability to produce sufficient energy on demand' [3], resulting into a (delayed) increase of typical symptoms, e.g. weakness, muscular and/or joint pain, cognitive deficits, after a minor physical or mental exertion, with prolonged "recovery" times $[4,5]$.

\section{The Impact of Exertion on the Physical Exercise Capacity}

A cardiopulmonary test (CPET) is considered an accurate method for assessing function [6]. The ventilatory or anaerobic threshold indicates the workload and oxygen consumption at which the anaerobic metabolism begins to predominate [7]. Therefore a negative effect of a CPET on this threshold and the accompanying oxygen uptake partly reflects the physical dimension of post-exertional malaise.

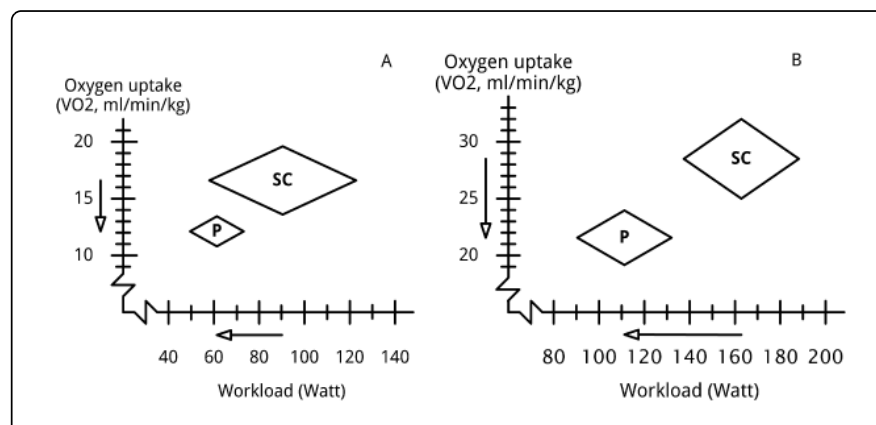

Figure 1: Exercise performance levels of ME/CFS patients compared to sedentary controls.

Although contradicted by some studies, e.g. [8] and [9], several studies (Table 1) have observed an extremely low exercise capacity when compared to sedentary healthy controls as illustrated in Figure 1. This is reflected by the low power output and oxygen uptake at the anaerobic threshold (W AT, respectively VO2 AT) or at the ventilatory threshold (W VT, respectively VO2 VT) and at exhaustion (Wmax and VO2max) at a CPET, despite sufficient effort, as implicated by the respiratory exchange ratio at exhaustion (RERmax). The average VO2max of $21.9 \mathrm{~mL} / \mathrm{min} / \mathrm{kg}$ observed at the first CPET by Keller et al. 
Citation: Twisk FN (2015) Objective Evidence of Post-exertional "Malaise" in Myalgic Encephalomyelitis and Chronic Fatigue Syndrome. J Sports Med Doping Stud 5: 159. doi:10.4172/2161-0673.1000159

Page 2 of 6

[7] for example is only $77.1 \%$ of the predicted VO2max for age/sexmatched sedentary controls [10].

The left and lower corner of the diamonds indicate the minimum performance levels and the right and upper corner of the diamonds reflect the maximum performance levels of sedentary controls (SC) and ME/CFS patients (P) observed in the exercise tests studies summarized in Table 1a) effort and oxygen uptake the ventilator y or anaerobic threshold, and b) effort and oxygen uptake at maximum effort.

Looking at the observations it seems likely that the exercise capacity of ME/CFS patients is profoundly compromised when compared to sedentary controls. This could explain easy muscle fatigability and profound "lack of energy" in ME/CFS.

\begin{tabular}{|c|c|c|c|c|c|c|c|c|c|c|c|c|c|c|}
\hline \multirow[t]{2}{*}{ Study } & \multicolumn{7}{|c|}{ ME/CFS patients } & \multicolumn{7}{|c|}{ Sedentary controls } \\
\hline & $\mathbf{N}$ & $\begin{array}{l}\text { WR } \\
\text { AT } \\
\text { (Watt) }\end{array}$ & $\begin{array}{l}\mathrm{VO2} \text { AT } \\
(\mathrm{mL} / \mathrm{min} / \\
\mathrm{kg})\end{array}$ & $\begin{array}{l}\text { WR VT } \\
\text { (Watt) }\end{array}$ & \begin{tabular}{|l} 
VO2 VT \\
$(\mathrm{mL} / \mathrm{min} /$ \\
$\mathrm{kg})$
\end{tabular} & $\begin{array}{l}\text { Wrmax } \\
\text { (Watt) }\end{array}$ & $\begin{array}{l}\text { VO2max } \\
(\mathrm{mL} / \mathrm{min} / \\
\mathrm{kg})\end{array}$ & $\mathbf{N}$ & $\begin{array}{l}\text { WR } \\
\text { AT } \\
\text { (Wa } \\
\text { tt) }\end{array}$ & $\begin{array}{l}\text { VO2 AT } \\
(\mathrm{mL} / \mathrm{min} / \\
\mathrm{kg})\end{array}$ & \begin{tabular}{|l|} 
WR VT \\
(Watt)
\end{tabular} & $\begin{array}{l}\mathrm{VO2} \quad \mathrm{VT} \\
(\mathrm{mL} / \mathrm{min} / \\
\mathrm{kg})\end{array}$ & $\begin{array}{l}\text { Wrmax } \\
\text { (Watt) }\end{array}$ & $\begin{array}{l}\text { VO2max } \\
(\mathrm{mL} / \mathrm{min} / \mathrm{kg})\end{array}$ \\
\hline $\begin{array}{l}\text { Snell et } \\
\text { al. 2013 } \\
{[6] \&}\end{array}$ & 1 & & & $\begin{array}{l}49.5 \pm \\
20.4 \dagger+\dagger \dagger\end{array}$ & $\left|\begin{array}{ll}12.7 & \pm \\
2.9 \dagger \dagger\end{array}\right|$ & $\begin{array}{l}109.6 \pm \\
28.9+\dagger \dagger\end{array}$ & $\begin{array}{ll}21.5 & \pm \\
4.1 \dagger & \end{array}$ & 10 & & & $\begin{array}{l}58.0 \pm \\
16.7\end{array}$ & $\begin{array}{ll}13.8 & \pm \\
2.8 & \end{array}$ & $\begin{array}{l}137.2 \pm \\
23.2\end{array}$ & $25.0 \pm 4.4$ \\
\hline $\begin{array}{l}\text { Keller et } \\
\text { al. 2014 } \\
\text { [7] \& }\end{array}$ & 2 & & & $\begin{array}{ll}51.4 & \pm \\
25.0 & \end{array}$ & $\begin{array}{ll}12.2 & \pm \\
3.7 & \end{array}$ & $\begin{array}{ll}122.7 & \pm \\
28.8 & \end{array}$ & $\begin{array}{ll}21.9 & \pm \\
4.8 & \end{array}$ & - & & & - & - & - & - \\
\hline $\begin{array}{l}\text { Vermeul } \\
\text { en et al. } \\
2010 \\
{[11] \&}\end{array}$ & 5 & $\begin{array}{l}8.6 \pm \\
24.2^{*}\end{array}$ & $\mid \begin{array}{ll}12.8 & \pm \\
3.0^{* *} & \end{array}$ & & & $\begin{array}{ll}132 & \pm \\
30.0^{* *} & \end{array}$ & $\left|\begin{array}{ll}22.3 & \pm \\
5.7^{* *}\end{array}\right|$ & 15 & $\begin{array}{l}2.9 \\
\pm \\
29 . \\
1\end{array}$ & $\begin{array}{ll}16.7 & \pm \\
4.0 & \end{array}$ & & & $\begin{array}{l}188.0 \pm \\
46.0\end{array}$ & $31.2 \pm 7.0$ \\
\hline \multirow{2}{*}{$\begin{array}{l}\text { Vermeul } \\
\text { en et al. } \\
2014 \\
{[12]}\end{array}$} & 78 & & $\begin{array}{ll}10.9 & \pm \\
2.6^{\wedge} & \end{array}$ & & & & $\begin{array}{ll}20.3 & \pm \\
5.0^{\wedge \wedge}\end{array}$ & 1 & & $\begin{array}{ll}13.7 & \pm \\
3.6 & \end{array}$ & & & & $27.4 \pm 7.2$ \\
\hline & 5 & & $\begin{array}{l}11.8 \\
2.8^{\wedge \wedge \wedge}\end{array}$ & & & & $\begin{array}{l}24.0 \\
7.2^{\wedge \wedge \wedge \wedge}\end{array}$ & 7 & & $\begin{array}{ll}13.7 & \pm \\
3.1 & \end{array}$ & & & & $27.3 \pm 3.7$ \\
\hline $\begin{array}{l}\text { De } \\
\text { Becker } \\
\text { et al. } \\
2000 \\
{[13]}\end{array}$ & 27 & $\begin{array}{l}2.8 \pm \\
1.5^{\star \star *}\end{array}$ & & & & $\begin{array}{ll}90.5 & \pm \\
1.6^{* \star *} & \end{array}$ & $\begin{array}{ll}20.5 & \pm \\
0.3^{* * *}\end{array}$ & 204 & $\begin{array}{l}23 . \\
0 \pm \\
2.7\end{array}$ & & & & $\begin{array}{l}162.9 \pm \\
2.7\end{array}$ & $32.0 \pm 0.6$ \\
\hline $\begin{array}{l}\text { Inbar et } \\
\text { al. 2001 } \\
\text { [14] }\end{array}$ & 5 & & $\begin{array}{l}13.5 \\
3.1^{* * *}\end{array}$ & & & & $\begin{array}{ll}19.8 & \pm \\
5.3^{* * *}\end{array}$ & 15 & & $\begin{array}{ll}19.2 & \pm \\
3.5 & \end{array}$ & & & & $27.3 \pm 5.6$ \\
\hline $\begin{array}{l}\text { Ickmans } \\
\text { et al. } \\
2013 \\
{[15]}\end{array}$ & 0 & & & & & $\begin{array}{l}114.2 \\
31.3^{\star \star \star}\end{array}$ & $\begin{array}{ll}19.1 & \pm \\
4.6^{\star \star * *}\end{array}$ & 13 & & & & & $\begin{array}{l}170.0 \pm \\
36.2\end{array}$ & $27.2 \pm 5.6$ \\
\hline $\begin{array}{l}\text { Aerenho } \\
\text { uts et al. } \\
2014 \\
{[16]}\end{array}$ & 2 & & & & & $\begin{array}{ll}117 & \pm \\
30.0^{* \star *}\end{array}$ & $\begin{array}{ll}19.5 & \pm \\
4.7^{* * *}\end{array}$ & 24 & & & & & $\begin{array}{l}172.0 \pm \\
33.0\end{array}$ & $29.9 \pm 5.5$ \\
\hline \multicolumn{15}{|c|}{ 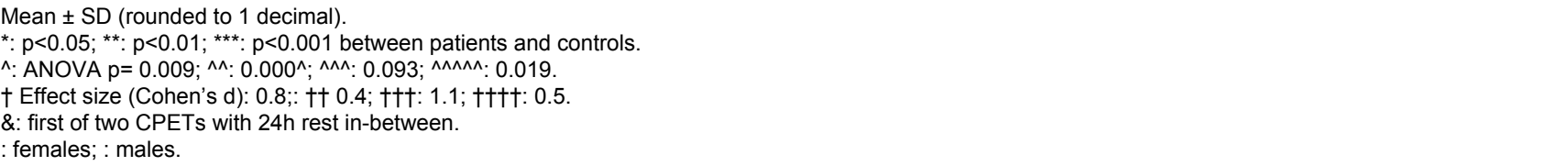 } \\
\hline
\end{tabular}

Table 1: Exercise performance levels of ME/CFS patients at a CPET in comparison with sedentary controls.

Although the enormous difference between the exercise performance levels of ME/CFS patients and those of sedentary controls seems to indicate otherwise, one could argue that this low exercise capacity is simply due to deconditioning. However, a phenomenon which is not observed in sedentary controls or patients with other diseases and seems to be unique to ME (CFS) is the profound negative effect of a CPET on the performance indicators 24 hours later at a second CPET.

Table 2 summarizes studies into the effect of a CPET (CPET1) on the performance at a second CPET (CPET 2) 24 hours in ME/CFS patients (Figure 2). To illustrate the size of the effect of CPET1 on the 
Page 3 of 6

performance levels at CPET2, in a recent study by Keller et al. [7] the $\mathrm{ME} / \mathrm{CFS}$ patient group as a whole showed significant decreases at CPET2 in VO2max (13.8\%), Wmax (12.5\%), VO2 VT (15.8\%), and W VT (21.3\%), when compared to CPET1. VO2max decreased in most patients. Patients whose VO2max did not change instead exhibited a decrease in VO2 VT. So, all patients presented with clinically significant decreases in either $\mathrm{VO} 2 \mathrm{max}$ and/or VO2 VT exceeding the well-established normative variation of $\leq 7 \%$. Even if ME/CFS patients are able to perform at levels comparable to sedentary controls in the first CPET, as e.g. seen in a study by Snell et al. [6], the performance levels of ME/CFS patients at the second CPET are substantially decreased, while in sedentary controls most performance indicators are slightly improved in the second CPET. Data from the study by Keller et al. [7] and other studies [6,11,12] implicate that aerobic energy-producing systems fails to respond adequately to exercise stress in ME/CFS.

\begin{tabular}{|c|c|c|c|c|c|c|c|c|c|c|c|c|c|}
\hline \multirow[t]{2}{*}{ Study } & \multirow[b]{2}{*}{$\mathbf{N}$} & \multicolumn{6}{|l|}{ CPET1 } & \multicolumn{6}{|l|}{ CPET2 } \\
\hline & & $\begin{array}{l}\text { WR } \\
\text { AT } \\
\text { (Watt) }\end{array}$ & $\begin{array}{ll}\mathrm{VO} 2 & \mathrm{AT} \\
(\mathrm{mL} / \mathrm{min} / \mathrm{kg})\end{array}$ & $\begin{array}{l}\text { WR } \\
\text { VT } \\
\text { (Watt) }\end{array}$ & $\begin{array}{lr}\text { VO2 } & \text { VT } \\
(\mathrm{mL} / \mathrm{min} / \mathrm{kg})\end{array}$ & $\begin{array}{l}\text { Wrma } \\
x \\
\text { (Watt) }\end{array}$ & $\begin{array}{l}\text { VO2max } \\
(\mathrm{mL} / \mathrm{min} / \mathrm{kg})\end{array}$ & $\begin{array}{l}\text { WR } \\
\text { AT } \\
\text { (Watt) }\end{array}$ & $\begin{array}{|lr|}\text { VO2 } & \text { AT } \\
(\mathrm{mL} / \mathrm{min} / \mathrm{kg})\end{array}$ & \begin{tabular}{|l|} 
WR VT \\
(Watt)
\end{tabular} & $\begin{array}{ll}\mathrm{VO} 2 & \mathrm{VT} \\
(\mathrm{mL} / \mathrm{min} / \mathrm{kg})\end{array}$ & $\begin{array}{l}\text { Wrma } \\
\text { X } \\
\text { (Watt) }\end{array}$ & $\begin{array}{l}\text { VO2max } \\
(\mathrm{mL} / \mathrm{min} / \mathrm{kg})\end{array}$ \\
\hline $\begin{array}{l}\text { Snell et al. } \\
2013 \text { [6] }\end{array}$ & $\begin{array}{l}5 \\
1\end{array}$ & & & $\begin{array}{l}49.5 \pm \\
20.4\end{array}$ & $12.7 \pm 2.9$ & $\begin{array}{l}109.6 \pm \\
28.9\end{array}$ & $21.5 \pm 4.1$ & & & $\begin{array}{l}22.2 \pm \\
18.5 \\
(-55.2 \\
\left.\%,{ }^{*}\right)\end{array}$ & $\left|\begin{array}{l}11.4 \pm 2.9 \\
\left(-10.8 \%,{ }^{*}\right)\end{array}\right|$ & $\begin{array}{l}101.6 \pm \\
30.7 \\
(-7.2 \% \\
\left.{ }^{*}\right)\end{array}$ & $\begin{array}{l}20.4 \pm 4.5 \\
\left(-5.0 \%,{ }^{*}\right)\end{array}$ \\
\hline 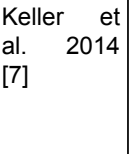 & $\begin{array}{l}2 \\
2\end{array}$ & & & $\begin{array}{l}51.4 \pm \\
25.0\end{array}$ & $12.2 \pm 3.7$ & $\begin{array}{l}122.7 \pm \\
28.8\end{array}$ & $21.9 \pm 4.75$ & & & $\begin{array}{l}41.4 \quad \pm \\
28.8 \\
(-21.3 \\
\%, \quad p=. \\
030)\end{array}$ & $\begin{array}{l}9.9 \pm \quad 2.89 \\
(-15.8 \%, \quad p=. \\
003)\end{array}$ & $\begin{array}{l}105.7 \pm \\
33.57 \\
(-12.5 \\
\%, \quad p=. \\
012)\end{array}$ & $\begin{array}{l}18.6 \pm 4.06 \\
(-13.8 \%, p=. \\
000)\end{array}$ \\
\hline $\begin{array}{l}\text { Vermeulen } \\
\text { et al. } 2010 \\
\text { [11] }\end{array}$ & $\begin{array}{l}1 \\
5\end{array}$ & $\begin{array}{l}58.6 \pm \\
24.2\end{array}$ & $12.8 \pm 3.0$ & & & $\begin{array}{l}132 \pm \\
30.0\end{array}$ & $22.3 \pm 5.7$ & $\begin{array}{l}54.5 \pm \\
20.9 \\
(-7.0 \% \\
)\end{array}$ & $\begin{array}{l}11.9 \pm \quad \pm \quad 2.9 \\
(-7.0 \%)\end{array}$ & & & $\begin{array}{l}125.0 \pm \\
35.0 \\
(-5.3 \%)\end{array}$ & $\begin{array}{ll}20.9 \pm & \pm .5 \\
(-6.3 \%, & \\
p<0.01) & \end{array}$ \\
\hline $\begin{array}{l}\text { VanNess } \\
\text { et al. } \\
2006 / 2007 \\
{[17,18]}\end{array}$ & 6 & & $15.0 \pm 4.9$ & & & & $26.2 \pm 4.9$ & & $\begin{array}{l}11.0 \pm 3.4 \\
\left(-26.7 \%,{ }^{*}\right)\end{array}$ & & & & $\begin{array}{l}20.5 \pm 1.8 \\
\left(-21.8 \%,{ }^{*}\right)\end{array}$ \\
\hline
\end{tabular}

Table 2: Exercise performance levels of ME/CFS patients at repeated CPETS.

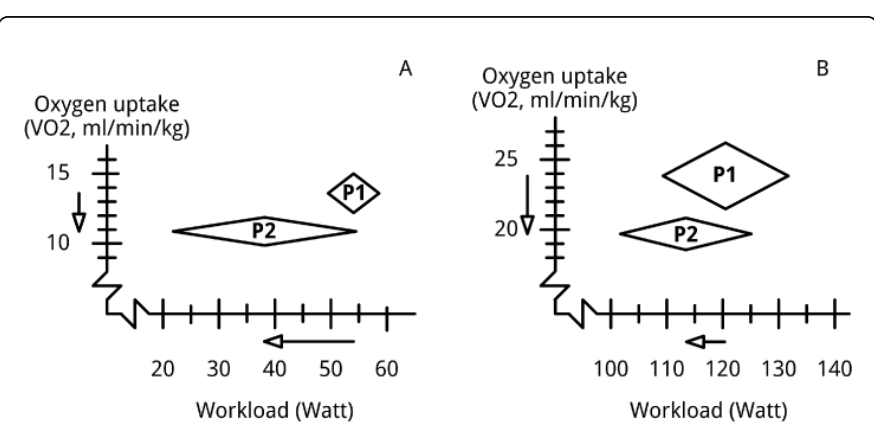

Figure 2: Effect of a CPET (CPET1) on the exercise performance indicators at a second CPET (CPET2) 24 hours later in ME/CFS.

The left and lower corner of the diamonds indicate the minimum performance levels and the right and upper corner of the diamonds reflect the maximum performance levels of ME/CFS patients (P) observed in repeated exercise tests studies (Table 2). a) effort and oxygen uptake the ventilator y or anaerobic threshold, and b) effort and oxygen uptake at maximum effort. P1: performance indicators at CPET1, P2: performance level indicators at CPET2.

\section{The Impact of Exertion on Cognitive Functioning}

Although contradicted by some studies, several studies observed mild to substantial deficits in the speed of processing of simple and complex information [19] and in cognitive tasks which require working memory over a longer period of time (endurance) $[19,20]$, (concurrent) processing of information [21,22] and conflictmonitoring (interference control) [23]. Cognitive deficits, especially impairments related to attention, memory and reaction times, only seem to manifest themselves if adequate tests and measured are employed [24]. This relevant observation is substantiated by a meta review of 79 cognitive tests applied in studies [19]. All tests for attention, including attention span and working memory, showed significant deficits in ME/CFS and all five tests aimed at reaction times disclose impairment for responses to both simple and complex (choice) stimuli. However, specific word list learning and recall tests seem to be more sensitive than others to the memory deficits reported by ME/CFS patients.

Although research into the effects of physical exercise on cognitive functioning is limited, studies seem to implicate that exertion has a (prolonged) negative impact on cognitive performance, e.g. focused and sustained attention [25], simple reaction time and choice reaction times [26], cognitive speed and disinhibition, psychomotor speed and vigilance [27]. This negative effect seems to oppose the positive effect of exercise on cognitive performance observed in sedentary controls 
[27]. In a study by Blackwood et al. [25], ME/CFS patients, patients with major depressive disorder and healthy controls were subjected to a cognitive test battery before and after five minutes of recovery of a treadmill exercise test to a target of $85 \%$ age-predicted maximum heart rate (220 - age in years). ME/CFS patients exhibited a greater decrease than healthy controls on everyday tests for focused $(p=0.02)$ and sustained $(\mathrm{p}=0.001)$ attention, as well as greater deterioration than depressed patients on the focused attention task $(\mathrm{p}=0.03)$ after the exercise test, despite subjective and objective evidence of effort allocation. VanNess et al. [26] observed that the ME/CFS patient group was slower on all measures for simple reaction time and choice reaction time after a graded exercise test to exertion when compared to sedentary controls. Comparing the scores of a cognitive test battery (4 tests) before, immediately after, and 24 hours post-treadmill exercise to exhaustion of Lamanca et al. [27] found that while no differences were observed pre-exercise, patients improved at a slower rate than sedentary healthy controls on the Symbol Digit Modalities Test, the Stroop Word Test, and the Stroop Color Test. When compared to the controls, a lower number of correct responses were observed on all three tests immediately post-exercise and 24 hours after the exercise test.

\section{Orthostatic Stress and Cognitive Impairment}

Orthostatic stress also seems to induce or intensify cognitive deficits in ME/CFS.

A ME/CFS patient subgroup exhibits (delayed) orthostatic intolerance [28], implicated by a profound increase of the heart rate and/or decrease of the blood pressure in an upright position [29]. A deterioration of scores and reaction times on the n-back test as orthostasis progresses $[30,31]$ indicates that orthostatic stress has a negative impact on working memory and information processing in ME/CFS. In the n-back task [32] the subject is presented with a sequence of stimuli, e.g. letters, and the task consists of indicating when the current stimulus matches the one from $\mathrm{n}$ steps earlier in the sequence. A recent study [33] found that head-up tilt (HUT) induced a significant rise in the n-back normalized response time in ME/CFS compared with supine, a phenomenon not observed in healthy controls. HUT caused cerebral blood flow velocity to fall $8.7 \%$ in controls and $22.5 \%$ in ME/CFS.

\section{Muscle Power (Strength and Endurance) and the Effects of Muscle Exercise}

Various studies have observed reduced muscle power (strength and endurance) in ME/CFS. Neu et al. [34] e.g. found reduced hand grip strength during tonic trials. They also observed that patients exhibited higher fatigability during phasic trials, in which a subject must grip the handle as strongly as possible and relax immediately during successive trials, with a significant decline of the maximal grip strength at the end of the ten phasic trials. Siemionow et al. [35] observed that the hand grip strength of patients was significantly lower than that of sedentary controls and that the maximum voluntary contraction force in the ME/CFS group dropped significantly to $83 \%$ of the strength at baseline after 50 contractions with 10 s and 50 contractions with 5 s rest between contractions. Lawrie et al. [36] observed that patients were able to sustain a $10 \mathrm{~kg}$ handgrip contraction less shorter than healthy controls, and Fulcher and White [37] found that the maximum twitch interpolated isometric contraction force of the quadriceps muscle of the dominant leg was significantly lower patients compared to sedentary controls.

Next to reduced muscle power (endurance), recovery of muscle exercise seems to be prolonged or inadequate. In a study by Paul et al. [38] ME/CFS patients and healthy sedentary controls were subjected to an exercise comprising 18 maximum voluntary contractions (MVCs) of the quadriceps (10s contraction, 10s rest). The MVC forces in the controls were consistently higher than those of the patients, with a decline in force during the exercise in both groups. Recovery was prolonged in the ME/CFS patient group, with a significant fall in the MVCs in the recovery phase (200 minutes) and at 24 hours postexercise ( $73 \pm 9 \%$ of the baseline MVC force levels). Recently Meeus et al. [39] found that patients exhibited reduced MVC levels for handgrip strength and insufficient, delayed recovery in the 45 minutes after intensive muscle exercise (18 maximum contractions lasting 5 seconds with 5 seconds rest in-between), when compared to MS patients and sedentary controls.

\section{Discussion}

Muscle (weakness), cognitive deficits, neurological impairments, and in particular post-exertional "malaise" are mandatory elements of ME and optional features for the diagnosis CFS: (persistent or relapsing) chronic fatigue. There is controversy about the diagnosis, the nature of the symptoms and potentially effective therapies.

Virtually all research into ME and CFS up to day is based upon subjective measures and questionnaires. In order to resolve the debate and to develop effective therapies for ME and CFS, its seems essential to make a distinction between people with muscle (weakness), cognitive deficits and post-exertional "malaise", designated as ME, and patients with "chronic fatigue" but without this characteristic symptoms, labeled as CFS, and to assess ambiguous symptoms, e.g. muscle weakness and post-exertional "malaise", employing objective methods. The relevance of a distinction between ME and CFS has been contested by some authors $[3,40,41]$. Although one could ask oneself whether the new diagnostic criteria for ME [3] are too restrictive or not, but numerous studies have pointed out that the need for a more concise definition of ME and emphasized the disparity between patients with distinctive symptoms, e.g. post-exertional "malaise" and patient without these symptoms [42].

Objective methods for assessing characteristic symptoms and pattern recognition analysis methods for diagnostic criteria should be employed to develop more effective strategies for future research into $\mathrm{ME}$ and CFS and for clinical practice.

Although various aspects of post-exertional malaise (an amplification of symptoms after a minor exertion) can be assessed objectively, e.g. the effects of exercise and orthostatic stress on physical functioning, cognitive performance, and muscle power, due to their subjective nature, other aspects of post-exertional malaise, e.g. a (prolonged) increase of pain and "fatigue" after exertion, cannot be quantified. However, looking at various findings [1] exercise-induced exacerbation of these symptoms can plausibly be explained, e.g. by an long-lasting increase of metabolite-responsive pain receptors and a impaired stress system response to exertion [43].

\section{Conclusion}

Post-exertional malaise, a long-lasting increase of typical symptoms after what is considered to be a minor exertion, is a distinctive 
phenomenon of ME (CFS). Several studies have demonstrated that the potentially profound impact of exertion and orthostatic stress on characteristic symptoms of ME (CFS), e.g. physical functioning, cognitive symptoms and muscle weakness, can be quantified using objective tests (Figure 3). To end the debate about the diagnosis, the nature of the symptoms and the effect of therapies, objective methods and measures should be employed.

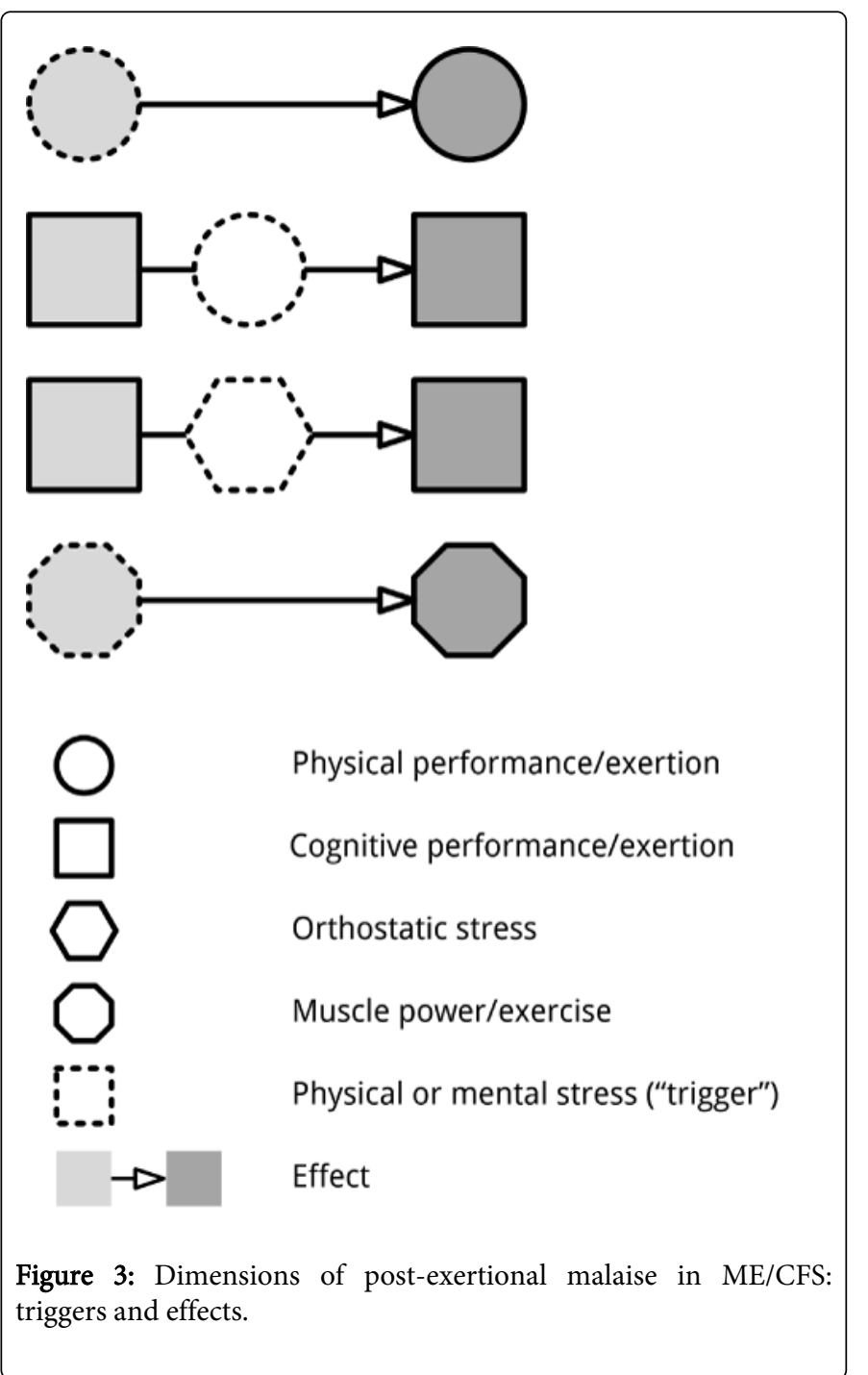

\section{References}

1. Twisk FN (2014) The status of and future research into Myalgic Encephalomyelitis and chronic fatigue syndrome: the need of accurate diagnosis, objective assessment, and acknowledging biological and clinical subgroups. Front Physiol 5: 109.

2. Twisk FN (2014) A definition of recovery in myalgic encephalomyelitis and chronic fatigue syndrome should be based upon objective measures. Qual Life Res 23: 2417-2418.

3. Carruthers BM, van de Sande MI, De Meirleir KL, Klimas NG, Broderick G, et al. (2011) Myalgic encephalomyelitis: International Consensus Criteria. J Intern Med 270: 327-338.

4. VanNess JM, Stevens SR, Bateman L, Stiles TL, Snell CR (2010) Postexertional malaise in women with chronic fatigue syndrome. J Womens Health (Larchmt) 19: 239-244.
5. Stiles TL, Snell CR, Stevens SR, Moran M, VanNess JM (2007) Postexertional symptomology in chronic fatigue syndrome (CFS). Med Sci Sports Exerc 39: S445.

6. Snell CR, Stevens SR, Davenport TE, Van Ness JM (2013) Discriminative validity of metabolic and workload measurements for identifying people with chronic fatigue syndrome. Phys Ther 93: 1484-1492.

7. Keller BA, Pryor JL, Giloteaux L (2014) Inability of myalgic encephalomyelitis/chronic fatigue syndrome patients to reproduce VO2 peak indicates functional impairment. J Transl Med 12: 104.

8. Sargent C, Scroop GC, Nemeth PM, Burnet RB, Buckley JD (2002) Maximal oxygen uptake and lactate metabolism are normal in chronic fatigue syndrome. Med Sci Sports Exerc 34: 51-56.

9. Bazelmans E, Bleijenberg G, Van Der Meer JW, Folgering H (2001) Is physical deconditioning a perpetuating factor in chronic fatigue syndrome? A controlled study on maximal exercise performance and relations with fatigue, impairment and physical activity. Psychol Med 31: 107-114.

10. Bruce RA, Kusumi F, Hosmer D (1973) Maximal oxygen intake and nomographic assessment of functional aerobic impairment in cardiovascular disease. Am Heart J 85: 546-562.

11. Vermeulen RC, Kurk RM, Visser FC, Sluiter W, Scholte HR (2010) Patients with chronic fatigue syndrome performed worse than controls in a controlled repeated exercise study despite a normal oxidative phosphorylation capacity. J Transl Med 8: 93.

12. Vermeulen RC, Vermeulen van Eck IW (2014) Decreased oxygen extraction during cardiopulmonary exercise test in patients with chronic fatigue syndrome. J Transl Med 12: 20.

13. De Becker P, Roeykens J, Reynders M, McGregor N, De Meirleir K (2000) Exercise capacity in chronic fatigue syndrome. Arch Intern Med 160: 3270-3277.

14. Inbar O, Dlin R, Rotstein A, Whipp BJ (2001) Physiological responses to incremental exercise in patients with chronic fatigue syndrome. Med Sci Sports Exerc 33: 1463-1470.

15. Ickmans K, Clarys P, Nijs J, Meeus M, Aerenhouts D, et al. (2013) Association between cognitive performance, physical fitness, and physical activity level in women with chronic fatigue syndrome. J Rehabil Res Dev 50: 795-810.

16. Aerenhouts D, Ickmans K, Clarys P, Zinzen E, Meersdom G, et al. (2014) Sleep characteristics, exercise capacity and physical activity in patients with chronic fatigue syndrome. Disabil Rehabil.

17. VanNess JM, Snell CR, Stevens SR, Bateman L, Keller BA (2006) Using serial cardiopulmonary exercise tests to support a diagnosis of chronic fatigue syndrome. Med Sci Sports Exerc 38: S85.

18. VanNess MJ, Snell CR, Stevens SR (2007) Diminished cardiopulmonary capacity during post-exertional malaise. J Chr Fatigue Syndr 14: 77-85.

19. Cockshell SJ, Mathias JL (2010) Cognitive functioning in chronic fatigue syndrome: a meta-analysis. Psychol Med 40: 1253-1267.

20. Capuron L, Welberg L, Heim C, Wagner D, Solomon L, et al. (2006) Cognitive dysfunction relates to subjective report of mental fatigue in patients with chronic fatigue syndrome. Neuropsychopharmacology 31 : 1777-1784.

21. Tiersky LA, Johnson SK, Lange G, Natelson BH, DeLuca J (1997) Neuropsychology of chronic fatigue syndrome: a critical review. J Clin Exp Neuropsychol 19: 560-586.

22. DeLuca J, Johnson SK, Natelson BH (1993) Information processing efficiency in chronic fatigue syndrome and multiple sclerosis. Arch Neurol 50: 301-304.

23. van de Putte EM, Böcker KB, Buitelaar J, Kenemans JL, Engelbert RH, et al. (2008) Deficits of interference control in adolescents with chronic fatigue syndrome. Arch Pediatr Adolesc Med 162: 1196-1197.

24. Thomas M, Smith A (2009) An investigation into the cognitive deficits associated with chronic fatigue syndrome. Open Neurol J 3: 13-23.

25. Blackwood SK, MacHale SM, Power MJ, Goodwin GM, Lawrie SM (1998) Effects of exercise on cognitive and motor function in chronic 
Citation: Twisk FN (2015) Objective Evidence of Post-exertional "Malaise" in Myalgic Encephalomyelitis and Chronic Fatigue Syndrome. J Sports Med Doping Stud 5: 159. doi:10.4172/2161-0673.1000159

Page 6 of 6

fatigue syndrome and depression. J Neurol Neurosurg Psychiatry 65 541-546.

26. VanNess JM, Snell CR, Stevens SR, Stiles TL (2007) Metabolic and neurocognitive responses to an exercise challenge in chronic fatigue syndrome (CFS). Med Sci Sports Exerc 39: S445.

27. LaManca JJ, Sisto SA, DeLuca J, Johnson SK, Lange G, et al. (1998) Influence of exhaustive treadmill exercise on cognitive functioning in chronic fatigue syndrome. Am J Med 105: 59S-65S.

28. Streeten DH, Anderson GH Jr (1998) The role of delayed orthostatic hypotension in the pathogenesis of chronic fatigue. Clin Auton Res 8: 119-124.

29. Streeten David HP (1987) Orthostatic disorders of the circulation: mechanisms, manifestations and treatment. Ann Intern Med 107: 269-270.

30. Ocon AJ, Messer Z, Medow M, Stewart J (2012) Increasing orthostatic stress impairs neurocognitive functioning in chronic fatigue syndrome with postural tachycardia syndrome. Clin Sci (Lond) 122: 227-238.

31. Stewart JM, Medow MS, Messer ZR, Baugham IL, Terilli C, et al. (2012) Postural neurocognitive and neuronal activated cerebral blood flow deficits in young chronic fatigue syndrome patients with postural tachycardia syndrome. Am J Physiol Heart Circ Physiol 302: H1185H1194.

32. Jaeggi SM, Buschkuehl M, Perrig WJ, Meier B (2010) The concurrent validity of the $\mathrm{N}$-back task as a working memory measure. Memory 18 : 394-412.

33. Medow MS, Sood S, Messer Z, Dzogbeta S, Terilli C, et al. (2014) Phenylephrine alteration of cerebral blood flow during orthostasis: effect on $\mathrm{n}$-back performance in chronic fatigue syndrome. J Appl Physiol (1985) 117: 1157-1164.

34. Neu D, Mairesse O, Montana X, Gilson M, Corazza F, et al. (2014) Dimensions of pure chronic fatigue: psychophysical, cognitive and biological correlates in the chronic fatigue syndrome. Eur J Appl Physiol 114: 1841-1851.

35. Siemionow V, Fang Y, Calabrese L, Sahgal V, Yue GH (2004) Altered central nervous system signal during motor performance in chronic fatigue syndrome. Clin Neurophysiol 115: 2372-2381

36. Lawrie SM, MacHale SM, Cavanagh JT, O'Carroll RE, Goodwin GM (2000) The difference in patterns of motor and cognitive function in chronic fatigue syndrome and severe depressive illness. Psychol Med 30: 433-442.

37. Fulcher KY, White PD (2000) Strength and physiological response to exercise in patients with chronic fatigue syndrome. J Neurol Neurosurg Psychiatry 69: 302-307.

38. Paul L, Wood L, Behan WM, Maclaren WM (1999) Demonstration of delayed recovery from fatiguing exercise in chronic fatigue syndrome. Eur J Neurol 6: 63-69.

39. Meeus M, Ickmans K, Struyf F, Kos D, Lambrecht L, et al. (2014) What is in a name? Comparing diagnostic criteria for chronic fatigue syndrome with or without fibromyalgia. Clin Rheumatol.

40. van der Meer JW, Lloyd AR (2012) A controversial consensus--comment on article by Broderick et al. J Intern Med 271: 29-31.

41. Broderick G (2012) Response to 'A controversial consensus'; by the International Consensus Panel. J Intern Med 271: 213-217.

42. Fischer DB, William AH, Strauss AC, Unger ER, Jason L, et al. (2014) Chronic Fatigue Syndrome: The Current Status and Future Potentials of Emerging Biomarkers. Fatigue 2: 93-109.

43. Habib KE, Negrao AB, Yasuda MR, Deuster P, Gold PW (2002) Altered interrelation among plasma stress hormones during treadmill exercise in females with chronic fatigue syndrome. 